\section{El evangelio y la riqueza: el paradigma cristológico en 2 Cor. 8-9}

Juan Stam*

\section{RESUMEN}

El presente trabajo pone énfasis en el paradigma cristológico planteado por Pablo en 2 Cor. 8.9: Cristo, Dios, abundantemente rico se hizo pobre, siervo, carne, pecado, maldición. El autor analiza el contexto, la ofrenda que los Corintios deben enviar a los pobres de Jerusalén, e interpreta dicho texto a la luz de las Escrituras: Profetas, Salmos, Levítico. El análisis marca distancia entre la llamada teología de la prosperidad y el mensaje de Pablo en relación con la riqueza. La reflexión termina examinando la literatura apocalíptica judeocristiana, señalando que la abundancia es para todos, en igualdad.

\section{PALABRAS CLAVE}

Paradigma cristológico, Ofrenda, Teología de la prosperidad, Literatura apocalíptica, Libertad, Igualdad.

\footnotetext{
* Tiene una Maestría en Teología de la Universidad de Columbia y un Doctorado en Teología por la Universidad de Basilea. Discípulo de Karl Barth . Ha publicado numerosos ensayos en revistas nacionales e internacionales.
}

\begin{abstract}
The present article emphasizes the Christological paradigm presented by Paul in II Cor.8.9: Christ, God, abundantly rich became poor, servant, flesh, sin, and curse. The author analyzes the context, the offering that the Corinthians should send to poor people from Jerusalem. He interprets this text in the light of the Scriptures: Prophets, Psalms, and Leviticus. The analysis differentiates between the so call prosperity theology and Paul's message in relation to wealth. The reflection finishes examining the Judeo-Christian apocalyptic literature by pointing out that the abundance is equal for everyone.
\end{abstract}

\section{KEY WORDS}

Christological paradigm, Offering, Prosperity Theology, Apocalyptic literature, Freedom, Equality.

Porque ya conoceis la gracia de nuestro Señor Jesucristo, que por amor a vosotros se hizo pobre, siendo rico, para que vosotros con su pobreza fueseis enriquecidos. (2 Cor 8.9).

Debe ser axiomático para todos los que nos llamamos cristianos, que el modelo supremo de nuestra vida, nuestras actitudes y nuestra conducta, tiene que ser el mismo Jesús, según las escrituras. Jesús advertía en muchas ocasiones contra el amor al dinero y a la riqueza y dijo que es imposible servir a Dios y a Mamón (dinero, riqueza). En este texto de 2 Corintios, Jesús

Rec. 15-06-2005 Aprob. 20-2-2006. 
mismo nos da el ejemplo, despojándose de sus propias riquezas para compartir con los demás.

Otro pasaje, el gran himno cristológico de Filipenses 2, nos cuenta que Cristo, siendo Señor de señores, aceptó venir a esta tierra en forma de siervo. Y nos dice el texto, "no estimó el ser igual a Dios como cosa a qué aferrarse" (Fil 2.6). Llama la atención que estos y otros cambios en la vida de la segunda persona de la trinidad son siempre cambios de Dios el Hijo hacia lo contrario de lo que había sido y de lo que esperaríamos de Dios: el Verbo se hizo carne Jn 1:14; el Señor se hizo siervo Fil 2:6-8; el Rico se hizo pobre 2 Cor 8:9; el Justo fue hecho pecado 2 Cor 5:21; y el Amado fue hecho maldición Gal 3.13. Todos son una especie de "movilidad social" hacia abajo (se hizo pobre, siervo, carne, pecado, maldición).

\section{El contexto de 2 Corintios 8 y 9}

San Pablo, al ir concluyendo su labor misionera, tuvo el gran sueño

de llevar a Jerusalén una comitiva de los primeros creyentes (las primicias) de las diversas provincias romanas que él había evangelizado, junto con una generosa ofrenda para los pobres (Rom 15.25-28; 1 Cor 16.1-4; Hch 20.22-24; 21.4,10-14;
Gál 2.10). En eso tuvo una doble intención: aliviar la extrema pobreza de los santos de Jerusalén y, segundo, dar un gesto de unidad de la iglesia, ya que las relaciones entre la iglesia de Jerusalén y la misión de Pablo habían sido tirantes. Pablo sabía bien que esa misión sería peligrosa, aun para su vida, pero se mantuvo inconmovible en su propósito.

En los preparativos para esa misión a Jerusalén, Pablo visitó las distintas iglesias solicitando ofrendas para llevar consigo a Jerusalén. En esas giras, tanto la iglesia de Macedonia como la de Corinto habían prometido sus aportes. Los hermanos de Macedonia, desde su pobreza y con mucho sacrificio, habían cumplido lo prometido (8.1-6), pero los de Corinto no (8.7-8). En ese contexto, es claro que Pablo escribe aquí para presionar a los corintios a entregar lo que habían prometido.

Lo sorprendente es que, para pedir fondos, Pablo no apela a la lástima ni al deber, sino a la gracia de Dios.1 En ningún momento apela a la lástima o la filantropía. Palabras como eleêmosunê (misericordia) o filanthropia (filantropía) o agathô-

1. Algunos párrafos a continuación son adaptados de mi escrito, "La sobreabundancia de la multiforme gracia de Dios" En: Gracia, Cruz, Esperanza, Israel Batista ed (Quito: CLAI 2004). 
sunê (generosidad, beneficencia) no aparecen en todo el pasaje. Más bien, la palabra clave de los dos capítulos es jaris (gracia), que se usa diez veces: siete veces como designación de la ofrenda para los pobres de Jerusalén $(8.1,4,5,7,19$; $9.8,14)$, una vez para la gracia de Cristo (8.9), y dos veces con el sentido de gratitud (9.15 gracias a Dios por su don inefable; 8.16 gracias por la solidaridad de Tito). El apóstol no fundamenta su solicitud de fondos ni en la lástima ni en la necesidad misma, sino en toda una teología de la gracia divina realizada en la acción social por los necesitados.

A partir de este carácter de gracia que reviste la generosidad, Pablo utiliza otros términos teológicos para describir este proyecto de acción social. Son frases del más alto significado teológico, y Pablo las va acumulando para un máximo de énfasis. Esa sencilla contribución monetaria sería "la jaris de la koinonia de la diakonia (8:4). Será un acto de justicia (9.9-10, dikaiosunê). La diakonía de esta leitourgia no sólo suplirá la necesidad de los pobres sino que redundará en mucha eujaristia (9.12) y en mucha doxa (gloria) para Dios (9:13). De esta forma el Apóstol invoca una serie de los términos teológicos más elevados, todo para describir una recolecta monetaria para los pobres. Ese ofrenda era una koinonía, una diakonía, una liturgia y una eucaristía.

El compartir con los necesitados es un carisma (jarisma) que el Espíritu otorga dentro del cuerpo de Cristo ("los que ayuden a otros", 1 Co 11.28). La gracia de Dios se revela en la generosidad cristiana con los pobres. Nuestro Dios es un Dios que da alimento a todo ser viviente (Sal 136.25; Eclo 7.32-33); como Dios de gracia y misericordia, es el Dios de los necesitados y las viudas, el Padre de los huérfanos y el defensor de los desahuciados. H.H. Eller afirma que en la enseñanza de Jesús, járis nunca tiene el sentido de "favor inmerecido", sino que consistía esencialmente en la solidaridad de Dios con los débiles, pobres, despreciados y desesperanzados (Mt 11.5,28-30; $\mathrm{Mr}$ 10.26-28; Lc 15). ${ }^{2}$

Tres textos resumen el argumento de estos dos capítulos:

1. 8.9 el modelo cristológico, que siendo rico se hizo pobre;

2. 9.8-11 Dios es poderoso para hacer que abunde en vosotros toda gracia, para que tenien-

2. H.H. Eller, "Gracia" en Coenen et al., Diccionario teológico del Nuevo Testamento (Salamanca: Sígueme 1980), Tomo II, p. $237-238$ 
do en todo lo suficente, estéis enriquecidos en todo para toda liberalidad;

3. 9.15 ¡Gracias a Dios (járis) por su don inefable! (nuestra respuesta eucarística).

¿En qué sentido era "rico" Cristo antes de encarnarse? A primera vista responderíamos "espiritualmente rico", pues en el cielo no existen bienes materiales. Sin embargo, eso rompería el paralelismo con la segunda frase (Jesús no era pobre espiritualmente sino materialmente) y no concordaría con el énfasis económico de todo el pasaje. No era un mensaje "espiritual" que Pablo quería comunicar a los corintios.

En el pensamiento hebreo, Dios es el dueño de toda la tierra, y Dios es el único dueño. "De Jehová es la tierra y su plenitud; el mundo y los que en él habitan" (Sal 24.1). "Pues míos son todos los animales salvajes, lo mismo que los ganados de las serranías; mías son las aves de las montañas y todo lo que bulle en el campo. Si yo tuviera hambre, no te lo diría a ti, pues el mundo es mío, con todo lo que hay en él" (Sal 50.10-12, Dios Habla Hoy).

Básica a la teología de la tierra en las escrituras hebreas, es la convicción de que nadie puede ser dueño de nada, porque es Dios quien reparte la tierra entre los seres humanos, que no son más que mayordomos. Por eso, "la tierra no debe venderse a perpetuidad; la tierra es mía, y ustedes sólo están de paso por ella como huéspedes míos" (Lev 25.23 DHH) Por supuesto, no queda ninguna posibilidad del concepto de propiedad privada en esa teología.

Si el Hijo de Dios, Co-Propietario del universo entero, estuvo dispuesto a hacerse pobre para enriquecernos a nosotros, cuánto más debían los cristianos de Corinto compartir sus bienes con los pobres de Jerusalén.

Cristo, siendo rico, se hizo pobre. Su vida comenzó en un pesebre prestado y lo sepultaron en una tumba también prestada. Se crió en una familia de la clase obrera, y durante dieciocho años de su vida ejerció el oficio de carpintero (su ministerio profético, en cambio, duró sólo unos tres años). En una ocasión dijo, comparándose desventajosamente con las zorras y las aves, "las zorras tienen guaridas, y las aves de los cielos nidos; mas el Hijo de hombre no tiene donde recostar la cabeza" (Lc 9.58). Cristo bendijo a los pobres y denunció a los ricos (Lc 6.20,24; 18.25). Jesús optó libremente por ser pobre y encarnó para nosotros un estilo sencillo de vida. 
Después de citar el paradigma cristológico, Pablo introduce una serie de nuevos temas, pero en 2 Cor 9.8-11 aclara el sentido de la última frase de 8.9 , para que vosotros con su pobreza fueseis enriquecidos. Este pasaje del capítulo 9, muy citado por la teología de la prosperidad, merece un análisis cuidadoso:

Y poderoso es Dios para hacer que abunde en vosotros toda gracia, a fin de que, teniendo siempre en todas las cosas lo suficiente, abundéis para toda buena obra, como está escrito: Repartió, dio a los pobres; su justicia permanece para siempre. Y el que da semilla al que siembra y pan al que come, proveerá y multiplicará vuestra sementera, y aumentará los frutos de vuestra justicia, para que estéis enriquecidos en todo para toda liberalidad...

Dos frases aquí aclaran el enriquecimiento que Cristo nos da: "teniendo siempre en todas las cosas lo suficiente, abundéis para toda buena obra" y "para que estéis enriquecidos en todo para toda liberalidad" (que repite el mismo verbo de 8:9). Este lenguaje está muy lejos de una teología de la afluencia capitalista y consumista; habla sólo de "tener lo suficiente", que es lo que Dios quiere para todos sus hijos e hijas.
Específicamente, para los corintios, significaba tener suficiente para vivir con dignidad y también contribuir para los pobres de Jerusalén, lo que describe como "justicia". No dice nada de una situación económica holgada ni de una vida de abundancia de bienes materiales. Eso, por supuesto, estaría en total contradicción con el paradigma cristológico de 8:9.

Los predicadores de la prosperidad gustan hablar de "la ley de siembra y cosecha", en el sentido moderno de una ley de causa y efecto. Pero este texto (junto con 9.6-7) no sugiere que Pablo estuviera formulando alguna especie de "ley", en el sentido moderno de causa y efecto; lo de la siembra y la cosecha no es más que una ilustración. Además, todo el énfasis de estos versículos, como de los dos capítulos, es sobre la generosidad en compartir los bienes que tenemos, no en acumular más bienes. Debe notarse, también, que Pablo no está pidiendo para sí mismo ni para su labor misionera sino para los pobres de Jerusalén. Qué diferente a las "maratónicas" de algunos canales de televisión y emisoras de radio, que recaudan grandes cantidades de dinero pero lo que menos se les ocurriría es repartirlo entre los pobres. 
En los versículos finales del capítulo (9.11-14) Pablo describe la reacción en cadena que ocurre cuando compartimos con los pobres: El clímax de esta solicitud de ofrendas es un verdadero éxtasis de alabanza por las consecuencias de la gracia de Dios encarnada en ayuda a los pobres. En esa situación de extrema pobreza en Jerusalén, y de relativa comodidad en Corinto, la gracia de compartir hará nacer una nueva esperanza. Terminada la ingrata tarea de solicitar fondos, Pablo irrumpe en una cascada de júbilo que anticipa las consecuencias de la contribución de los corintios:

[Dios] hará que ustedes produzcan una abundante cosecha de justicia. Ustedes serán enriquecidos en todo sentido para que en toda ocasión puedan ser generosos, y para que por medio de nosotros la generosidad de ustedes resulte en acciones de gracias (eujaristia) a Dios. Esta ayuda (diakonia) que es un servicio sagrado (leitourgia) no sólo suple las necesidades de los santos sino que también redunda en abundantes acciones de gracias (eujaristia) a Dios. En efecto, al recibir esta demostración de servicio (diakonia), ellos alabarán $($ doxazô $)$ a Dios por la obediencia con que ustedes acompañan la confesión (homologia) del evangelio de Jesucristo, y por su generosa solidaridad (koinônia) con ellos y con todos. Además, en las oraciones de ellos por ustedes, expresarán el afecto que les tienen por la sobreabundante gracia (jaris, ¡la ofrendita de los corintios!) que ustedes han recibido de Dios.

¡Gracias (jaris) a Dios por su don inefable! (9.10-15 DHH).

Algo muy extraño y muy importante está ocurriendo aquí. En medio de la necesidad de los pobres de Jerusalén y la renuencia de los acomodados de Corinto, la gracia de Dios ha entrado en acción. Pablo da por sentado que los corintios van a responder y enviar su ofrenda y da rienda suelta a su fe y su exuberante imaginación creativa para anticipar todos los trascendentales resultados de dicha gracia. Nada indica que el aporte de ellos iba a ser de sumas grandes; lo grande sería la gracia de Dios en la práctica consecuente de ellos.

Y es que la praxis del amor eficaz logra una transformación de la realidad. La esperada ofrenda de los corintios ha transformado el círculo vicioso de la des-gracia en el círculo eucarístico de la gracia. La práctica de la justicia introduce situaciones totalmente nuevas, 
donde la gracia de Dios comienza a actuar en reacción de cadenas de bendición.

Para que haya igualdad (8.13-14). Hay otro énfasis en estos capítulos que merece atención especial. Dos veces en dos versículos Pablo insiste en el ideal cristiano de la igualdad:

No se trata de que por ayudar a otros ustedes pasan necesidad; se trata más bien de que haya igualdad. Ahora ustedes tienen lo que a ellos les falta; en otra ocasión ellos tendrán lo que les falta a ustedes, y de esta manera habrá igualdad (8:13-14 DHH).

El paradigma cristológico de 8.9, que domina todo este bloque textual, implica también un compromiso con la igualdad. Siendo inmensamente rico (según el pensamiento hebreo y paulino), Jesucristo quiso "anivelarse" con nosotros y vivir como un pobre entre los pobres (aunque tampoco en miseria).

De hecho, la igualdad es el principio central de toda la enseñanza social y económica de Israel.3 Partiendo del principio de que

3. Para este tema, he adaptado materiales de mi artículo, "El poder económico de la gran bestia" En: Apocalipsis y Profecía (Buenos Aires: Kairós, 1998).
Dios es el único dueño de todos los bienes, la legislación hebrea estaba diseñada para defender al pobre y buscar la mayor igualdad posible en el pueblo. ${ }^{4}$ El intento evidente del sistema socio-económico propuesto para Israel era evitar que la prohibición del hurto se malinterpretara como justificación de la acumulación desigual de riquezas. $^{5}$ Dios se declara padre de los huérfanos, abogado defensor de las viudas, y amigo protector de los extranjeros y los desahuciados (Dt 10.18; Sal 68.5; Ex 22.21-24). La visión profética es de una sociedad en que "todos vivirán sin temor, y cada cual podrá descansar a la sombra de su vid y su higuera" (Miq 4.4; Zac 3.10).

El tema de la legislación social de Israel es amplísimo, pero ahora sólo podemos mencionar un aspecto central: el año sabático

4. Bien observa Robert Gnuse que la legislación judía se concentra no en proteger los "derechos" de los poderosos sino en defender la vida de los débiles. (Eso la contrapone frontalmente con la ideología neoliberal). Gnuse cita el Talmud de Lv 19.15: la justicia es misericordia más que imparcialidad (1987:107), en contraste con las leyes babilónicas que castigaban más severamente los delitos de pobres contra ricos. Robert Gnuse, Comunidad y propiedad en la tradición bíblica, Verbo Divino, Estella, Navarra, 1987.

5. Gnuse ibid., 1987:87 
y el Jubileo. Las fiestas judías se configuraron mayormente por la experiencia histórica del éxodo, y se destaca entre ellas una triple secuencia a base de ciclos de siete. El séptimo día de cada semana se celebraba el Shabat, cada séptimo año se debía celebrar el año sabático de la tierra (Dt 15.1-11; Lv 25.1 7.18-22); y después de siete sábados de la tierra (49 años), el siguiente año debía ser un año de jubileo ( $\mathrm{Lv}$ 25.8-17,23-34; 27.16-25). La estructura simétrica de este ciclo, a base de sietes (derivado también de la creación), acentúa su importancia.

En resumen, el día del sábado significaba una declaración de libertad para el trabajo humano y el descanso semanal para la tierra y los animales (Ex 23.12). Por otra parte, el sábado de la tierra, entre sus varias versiones, incluía tres elementos: 1) barbecho de la tierra durante el año, con sus productos no cultivados designados para los pobres (Ex 23.10s; Lv 25.27; Neh 10.32); 2) la liberación de todo israelita bajo servidumbre (Ex 21.2-11; Dt 15.12-18; Jer 34.8-17); 3) la condonación de toda deuda contraída (Dt 15.1-11). Hoy día, ante la agobiante crisis de la deuda externa de los países del tercer mundo, esta teología del préstamo ha captado la atención de muchos líderes latinoamericanos (¡hasta de
Fidel Castro! Ocurrió en una consulta sobre la deuda externa en la Habana en los años 80).

El Jubileo se describe sólo en Lev. 25 y está menos documentado que el año sabático. Se menciona también en Lev. 27.17-24, Nm. 36.4 y Ezq. 46.17, con alusiones también en Jer. 34 ("promulgar cada uno libertad a su prójimo" 34.8,15,17) e Isa. 61 ("proclamar libertad a los cautivos" 61.1; "proclamar el año agradable de Yahvé" 61.2) y algunos otros pasajes. ${ }^{6} \mathrm{Su}$ base histórico-salvífica es la repartición original de la tierra en igualdad y justicia: "A los grupos más numerosos les darás una porción mayor, y a los grupos menos numerosos una porción menor", a cada tribu según el censo (Nm. 26.54; 33.54). El Jubileo formula legalmente lo que los profetas articulan moralmente cuando denuncian la acumulación de propiedades (Is. 5.8; Miq 2.2).

"Pregonareis libertad en la tierra a todos sus moradores" (Lv. 25.10) es la consigna del Jubileo. Y como no puede haber libertad sin justicia económica, el otro tema es la tierra familiar. Christopher Wright afir-

6. Lv 25, Isa 61 y Jer 34 emplean la misma expresion hebrea para "pregonar libertad" (QâRâA DeRôR), lo cual sugiere una relación directa entre los textos. El mismo verbo ocurre en "proclamar remisión" (QâRâA SheMTâH) en Dt 15.2. 
ma que el sistema socioeconómico de Israel "tenía dos características que contrastaban totalmente con la estructura económica cananea": 1) la distribución equitativa y 2) la inalienabilidad de la tierra, para que no pasara definitivamente a otras familias. ${ }^{7}$

Para lograr la justicia y la igualdad, el autor sacerdotal no confía simplemente en la conciencia moral y la buena voluntad, ni iniciativas individuales privadas; plantea más bien un sistema de legislación nacional con un plan detallado de reforma agraria cada 50 años (Lv. 26.10-17,23 34). En contraste con el neoliberalismo, diseñado a favor de los poderosos para crear desigualdad a base de la libre competencia y la no-intervención estatal, el Jubileo pretende legislar un sistema social que rectifique periódicamente la infraestructura económica para defender la máxima igualdad social. ${ }^{8}$

7. Wright, Anchor Bible Dictionary, 1992, Tomo III, p. 1025.

8. Wright, ibid., p.1029; Gnuse, op.cit. p. 87. La misma meta y los mismos métodos se ven en el amplio sistema hebreo de impuestos como sistema para redistribuir la riqueza a favor de los pobres. El neoliberalismo predica la reducción de impuestos, pero lo realiza a favor de los ricos (que a su vez colaborarán financiando las campañas electorales de ellos).
Es cierto que hay problemas históricos en cuanto a esta legislación, pero es claro que el Jubileo (junto con el año sabático) expresaba la profunda convicción de los autores bíblicos, especialmente los profetas. No cumplirlo era una violación del pacto, que Dios también castigaría (Lv. 26.34,43; 2 Cr. 36.21; Jer. 34.1618). Cuando no se cumplía, era por el pecado humano. Por eso, en los profetas, este doble tema va tomando dimensiones mesiánicas y escatológicas (Is. 35; 58; 61; Ez 47.14). ${ }^{9}$ Esta esperanza, postergada y profundizada a la vez, se expresa elocuentemente en Is. 61.1-3:

1a. El espíritu del Señor está sobre mí, porque el Señor me ha consagrado; me ha enviado a dar buenas nuevas a los pobres, a aliviar a los afligidos,

2a. anunciar libertad (QâRâA DeRôR) a los presos, libertad a los que están en la carcel, a anunciar (QâRâA) el año favorable del Señor, el día en que nuestro Dios nos vengan de nuestros enemigos.

Me ha enviado a consolar a todos los tristes,

3a. dar a los afligidos de Sión una corona en vez de ceniza,perfume de alegría en

9. Wright, Christopher, "Sabbatical Year" Anchor Bible Dictionary (NY: Doubleday 1992) Tomo V, p. 860. 
vez de llanto, cantos de alabanza en vez de desesperación... (DHH)

Siglos después, según San Lucas (4.18s), Jesús en su proclama inaugural aplica este pasaje jubilar (más una frase de Is. 58.6, otro pasaje jubilar) a su propio ministerio redentor. Igual que en Is. 61.2, "el año favorable del Señor", que proclama libertad a los cautivos, debe entenderse como el Jubileo. En este "manifiesto de Nazareth" Jesús asume el rol del Ungido que había de traer el Jubileo ("El Espíritu del Señor está sobre mí, porque me ha ungido" 4.18; cf. 3.22) e identifica las metas y valores de su Reino con los del Jubileo. Su ministerio era en verdad "buenas nuevas para los pobres"; sus milagros eran señales del Jubileo prometido.

La proclama de Jesús en Nazaret se reafirma en el día de Pentecostés. Como era el día del sábado al año sabático (séptimo día y séptimo año), era también el día de Pentecostés al año de jubileo (50 días, 50 años). Es impresionante ver el paralelo de Hch. 2 con Isa. 61 y Lc. 4 . Al inicio del capítulo "el Espíritu del Señor" viene ahora sobre la iglesia, cuerpo vivo del Mesías resucitado (Hch. 2.113; cf. Is. 61.1). Y al final del capítulo, la comunidad mesiánica practica el Jubileo y realiza "buenas nuevas para los pobres" con un proyecto de comedores populares (Hch. 2.4247; 4.31-5.11, 6.1-7). El ideal del año sabático, que "no habrá pobres entre ustedes" (Dt. 15.4), se realizó en la comunidad pentecostal: "No había entre ellos ningún necesitado" (Hch. 4.34) porque "ninguno decía ser suyo propio nada de lo que poseía" (4.32). En el día de Pentecostés, el Espíritu inspiró un verdadero Jubileo y un anticipo de la comunidad de bienes de la Nueva Jerusalen.

El proyecto económico que comenzó el día de Pentecostés se prolongó hasta el final del ministerio de San Pablo. Cuando Pablo y Bernabé subieron a Jerusalén para consultar con los apóstoles sobre la misión a los gentiles, éstos les dieron su aval pero "solamente nos pidieron que nos acordáramos de los pobres, cosa que he procurado hacer con todo cuidado" (Gál. 2.10 $\mathrm{DHH})$. Uno de los primeros proyectos de Pablo como cristiano fue el de llevar ayuda a los necesitados de Judea (Hch. 11.29s). Y al final de su ministerio, en el corazón de Pablo nace el sueño osado de juntar a los primeros creyentes de las comunidades gentiles y monedas de las distintas provincias del imperio, para llevarlo a Jerusalén para los pobres (Ro. 15.25-26; 1Co. 16.1-4; 2 Cor. 8-9; Hch. 20.22s; 21.10-14). Pablo dedicó la culminación de su ministerio al mismo proyecto de Jubileo que nació el día de Pentecostés. 
Esa visión escatológico-económica se realiza plenamente en Ap. 21-22. La igualdad es un valor bíblico; la desigualdad, un anti-valor antibíblico. En el reino de Dios todos seremos reyes y sacerdotes; nadie será más rey y sacerdote, nadie será menos rey y sacerdote. Entonces el oro y las perlas y las piedras preciosas, antes prostituídas en las manos del imperio, serán de todo el pueblo (las calles y muros y fundamentos del pueblo: Apoc. 21:9 21). De hecho, la visión de abundancia e igualdad con que concluye la Biblia no es sino la culminación de toda una teología bíblica de los bienes materiales. Desde el pentateuco hasta el Apocalipsis, la teología bíblica de lo económico es un mensaje de justicia e igualdad. La visión de la Nueva Jerusalén debe ser la inspiración y la orientación de los cristianos de hoy ante los desafíos complejos del futuro de nuestro continente.

La literatura apocalíptica judeocristiana, siguiendo fielmente esta larga tradición bíblica, hace también aportes valiosos a esta visión de abundancia para todos. Muy citada es 2 Baruc 29.4:

La tierra dará frutos diez mil veces mayor. Cada vid tendrá mil ramas, y cada rama producirá mil racimos de uvas, y cada racimo producirá mil uvas, y cada uva dará un cor de vino
[200 litros]...Y los hambrientos se gozarán y verán maravillas cada día. Vientos saldrán cada mañana de delante de mí a llevar la fragancia de frutos aromáticos, y nubes al final del día destilarán el rocío del cielo. $Y$ en aquel tiempo los tesoros del maná caerán de nuevo del cielo, y comerán de él.

La alusión al "maná escondido" en Ap. 2.17 muestra que Juan conocía la misma tradición de 2 Baruc 29 y corrobora el cuadro de abundancia para todos que nos dan los últimos capítulos del Apocalipsis.

Otra literatura antigua judeo-cristiana confirma dramáticamente el ideal de igualdad en el reino mesiánico:

...y todos disfrutarán de vida común y riqueza. La tierra será de todos por igual; sin estar dividida por muros ni cercados, producirá algún día frutos más abundantes. Y dará frutos de dulce vino, de blanca leche y de miel...cuando Dios haga cambiar los tiempos...y transforme el invierno en verano. (Oráculo Sibilino 8.208-215)

La tierra, de todos por igual, sin estar dividida por muros ni cercados, producirá entonces frutos más abundantes por sí sola. Compartirán los recursos sin dividir la riqueza, pues allí no habrá ni pobres ni ricos, ni 
amos ni esclavos, ni grandes ni pequeños, ni reyes ni caudillos. En común y unidos vivirán todos. (Or. Sib. 2.319-324)

Esta visión judeo-cristiana es el proyecto económico de Dios para la historia humana. Por ella oramos cuando decimos "venga tu reino, hágase tu voluntad, en la tierra como en el cielo". Nuestras opciones y nuestra conducta se orientan por el mandato de "buscar primeramente el reino de Dios y su justicia" (Mat. 6:33) y, en términos escatológicos, su abundancia y su igualdad. Cualquier otro programa es el proyecto de la bestia, no de Dios y su Cordero.

Muy de acuerdo con esta visión profética son las palabras de nuestro gran poeta costarricense, Jorge Debravo:

Yo deseo que todo, que la vida sea nuestra como el agua y el viento.

Que nadie tenga más patria que el vecino.

Que nadie diga más la finca mía... sino la finca nuestra, de nosotros los hombres.

(del poema "Nosotros los hombres")

Me gustaría tener manos enormes, violentas y salvajes, para arrancar fronteras una a una y dejar de frontera solo el aire.
Que nadie tenga tierra como se tiene tierra; que todos tengan tierra como tienen el aire.

(del poema "Nocturno sin patria")

\section{BIBLIOGRAFÍA}

Camargo, Jesús.1997. "Realidad económica y fe cristiana", Boletín Teológico \#65, enero-marzo,pp. 27-58 de Vaux, R. 1985. Instituciones del Antiguo Israel, Barcelona: Herder.

Eller, H.H., "Gracia" en Lothar Coenen et al., 1980, Diccionario teológico del Nuevo Testamento (Salamanca: Sígueme), Tomo II, p.237-238.

Gnuse, Robert,1987, Comunidad y propiedad en la tradición bíblica, Verbo Divino, Estella, Navarra.

Maertens, Thierry, 1964, Fiesta en honor de Yahvé(Madrid: Cristiandad ).

Richard, Pablo, 1998, "Ya es tiempo de proclamar un jubileo", Vida y Pensamiento 18:2 octubre , 7-34.

Stam, Juan, 1998, "El poder económico de la gran bestia" En: Apocalipsis y Profecía (Buenos Aires: Kairós).

Stam, Juan, 2004, “La sobreabundancia de la multiforme gracia de Dios" En: Gracia, Cruz, Esperanza, Israel Batista ed (Quito: CLAI ), pp. 25-40

Wright, Christopher, 1992, Wright, Anchor Bible Dictionary, Tomo III, pp. 10251029 .

Wright, Christopher, 1992, "Sabbatical Year" Anchor Bible Dictionary (NY: Doubleday) Tomo V, pp. 857-861. 